The increased number of over-75s is the main problem facing the Health Service. The only resource that will be available will be flexibility. The twin problems of policies to help elderly people with mental illness and to define the role of old people's homes must be tackled. The family practitioners, com munity nurses, volunteers, and neighbours of elderly people with mental illness can only do so much. A realistic residential policy must be worked out and the keystone of this must be the old people's homes

J A MUIR Gray J S RODGERS

Oxfordshi re Area Health Authority (Teaching),

Oxford

${ }^{1}$ Population Projections No 4 1973-2013, prepared by the Government Actuary. London, HMSO, 1974 Department of Health and Social Security, Health and Personal Social

${ }^{3}$ Department of Health and Social Security, Community Hospitals: Their Role and Development in the National Health Service. London, DHSS, 1974 Wallingford Community. Hospital Research Project. Oxford, Oxford Regional Hospital Board, 1973.

\section{What do community physicians do?}

SIR,-Dr A Roberts (17 July, p 178) was quite right in questioning whether I was not comparing the former medical officer of health $(\mathrm{MOH})$ with the present community physician. My contention is that the problems are still there to be dealt with.

The MOH in the past was the only professional to oversee the Victorian environment and the crude medicosocial problems of the day. As these were tackled and were held at bay a number of technicians had to be trained and later took on almost independent professional responsibilities regarding the environment, water, sewage, housing, cleansing, and the like. The same occurred in the personal services of domiciliary midwifery, health visiting, and mental health. The one essentia in the provision of these municipal community services was the legal requirement to make them work, a mandatory situation which does not apply to clinical medicine, where, if everyone will speak truthfully, most of my colleagues unquestioningly and automatically apply our Hippocratic tradition, but some do not.

It is this unique overall responsibility of the $\mathrm{MOH}$ to get things done in spite of everything which has disappeared. There is nothing in its place to cope immediately and decisively with emergencies or to provide that background of comprehensive professional knowl edge which is essential to medicosocial planning. This is why community physicians as successors of MOHs feel that their hands are tied behind their backs so that they are merely the spectators of situations which need their involvement. We have been translated into a defective, hospital-orientated, lay administrative system in which each section works like battery hens laying eggs at their own rate without regard to others, without any central communication or collation of information without any feedback from other sections, and without spirit. The present system has no central registry or mechanism for the interpretation or co-ordination of the snowstorm of circulars from the DHSS (Elephant droppings) which confine our every action.

Imagine the apoplexy of a surgeon if the rest of the team did their own thing in their own time or said they just didn't believe in surgery anyway. This is the present position for community physicians, but we are still supposed to sort out anything and everything as well as being involved throughout the planning process.

W S PARKeR

East Sussex Area Health Authority,

Brighton Health District,

Brighton, Sussex

Modified operation for ingrowing toenails

SIR,-Ingrowing toenails are one of the commonest conditions seen in surgical clinics. Operations, which tend to be left to junior staff, are frequently complicated by infection and later by nail regrowth due to an incompletely excised nail bed. We have, however, had very good results since using the following operation. It is usually performed under local anaesthesia, with a tourniquet.

An elliptical segment, including the edge of the nail and the inflamed nail fold, is excised (see figure). The incisions are cut down to the bone so that a V-shaped segment of inflamed tissue is removed. This ensures that all the nail bed and all infected granulation tissue are completely removed. The wound is then cleaned with an antiseptic solution.

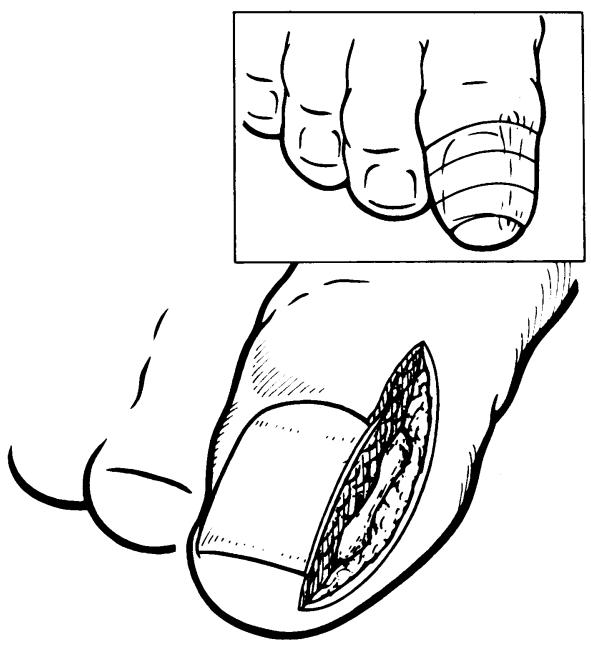

No sutures are used to close the defect instead, a length of Steristrip $\frac{1}{2}$ in $(13 \mathrm{~mm})$ is wrapped firmly around the toe. This produces very good approximation of the skin edges without leaving any open space beneath A firm bandage is applied before the tourniquet is removed. This dressing is left undisturbed for eight days if possible.

This operation has been performed on numerous occasions and has been charac terised by being surprisingly pain free and having a low incidence of infection.

B V PALMER

D LANG STEVENSON

Whipps Cross Hospital,

London E11

\section{Rebound hypertension after acute methyldopa withdrawal}

SIR,-We were interested in the report by Drs A C Burden and C T P Alexander (1 May, p 1056) of rebound hypertension after acute methyldopa withdrawal. Recently we observed a similar occurrence.
A 77-year-old hypertensive woman taking methyldopa $250 \mathrm{mg}$ twice daily and cyclopenthiazide was admitted with acute gouty arthropathy. Cyclopenthiazide was discontinued without alteration in blood pressure control at $130 / 80 \mathrm{~mm} \mathrm{Hg}$, and allopurinol treatment was begun. After one week the blood urea remained elevated at $12.6 \mathrm{mmol} /$ $(76 \mathrm{mg} / 100 \mathrm{ml}$ ) and it was considered that her blood pressure control might be excessive. Methyldopa was therefore withdrawn. Within a day her blood pressure had begun to rise, and 48 hours later, when it was 240/160 $\mathrm{mm} \mathrm{Hg}$, diazoxide $300 \mathrm{mg}$ was given intravenously with immediate good effect. Satisfactory blood pressure control was later again obtained with methyldopa $250 \mathrm{mg}$ twice daily.

In view of the fact that this patient's hypertension was easily controlled, both before and after cessation of therapy, by a small dose of methyldopa we consider the acute hypertensive crisis to have been a demonstration of rebound precipitated by acute methyldopa withdrawal. This would support Drs Burden and Alexander's suggestion that rebound hypertension occurs with hypertensive drugs other than clonidine.

J N ScotT

D G McDevitT

Belfast City Hospital and

Department of Therapeutics

and Pharmacology,

Queen's University,

Belfast

Short-term recovery of mental efficiency after anaesthesia

SIR,-The paper by Mr J E P Simpson and others (26 June, p 1560) is a beautiful piece of scientific research and writing, but the results are meaningless.

For day-case surgery the aim is to produce adequate intraoperative anaesthesia and postoperative recovery of consciousness which is as rapid and complete as possible. Premedication is part of the total anaesthetic management of a patient, and though the anaesthetic techniques compared by $\mathrm{Mr}$ Simpson and his colleagues are standard, premedication for day-case surgery is normally restricted to nitrazepam or some quiet reassurance. (If early recovery of consciousness is vital anaesthesia may be induced with propanidid rather than thiopentone.) Patients given a premedication of papaveretum $20 \mathrm{mg}$ and hyoscine $0.4 \mathrm{mg}$ would probably require $7-9$ hours to return to $60 \%$ of mental efficiency without any general anaesthetic.

I hope Mr Simpson and his colleagues will repeat their excellent study with alternative and lighter premedication.

E LL LLOYD

Department of Anaesthetics, Royal Infirmary,
Edinburgh

\section{Propranolol in hypertension}

SIR,-I believe that the article by Dr D B Galloway and others (17 July, p 140) might be seriously misleading in that they have not given sufficient emphasis to the fact that their study deals only with patients who are mildly hypertensive and who are treated with propranolol alone. The so-called "law of the initial value"1 2 suggests that the benefit of drugs may be proportionate to the severity of the condition treated, and my own experience 